\title{
Using Web 2.0 Learning Tools: Two Virtual Experiences*
}

\author{
Fernández, M.A. ${ }^{1}$; Muñoz, M.J. ${ }^{1}$ Rivera, J.M. ${ }^{1}$; León, R. ${ }^{2}$; Escrig, E. ${ }^{1}$; Ferrero, I. \\ ${ }^{1}$ Finance and Accounting Department, Universitat Jaume I (Spain) \\ ${ }^{2}$ Business Management and Marketing, Universitat Jaume I (Spain) \\ afernand@uji.es,munoz@uji.es,jrivera@uji.es,rleon@uji.es, eescrig@uji.es, \\ ferrero@uji.es
}

\begin{abstract}
The main purpose of this work is to present successful learning experiences based on creativity, innovation and the use of Information and Communications Technologies (ICT) to develop training practices in the area of Corporate Social Responsibility (CSR). The learning experiences consist in the development of an ontology for the knowledge domain of Corporate Governance, and a case-method learning activities focused on enhancing the understanding of CSR integration in a state-owned organisation. Results point out that the use of Web 2.0 applications in teaching activities has successfully contributed to the students' learning processes.
\end{abstract}

Keywords: E-learning, educational innovation, Web 2.0, Information and Communications Technologies (ITC), Corporate Social Responsibility (CSR)

\section{Introduction}

In the context of Bologna Process, a key issue of the Higher Education Area is to prepare students for their future careers as well as maximize their personal development and their contribution to a sustaina- ble and democratic knowledge-based society. In this regard, creativity, innovation and the use of new technologies have been recognized as essential elements for the future success of education, since they may considerably increase the competitiveness of the labour market and improve the social cohesion.

The research presented in this paper was addressed to the students within the subject "CSR Management" of the "Master in Sustainability and Corporate Social Responsibility". This master is online and since its first edition (2007) has done a wide use of information and communication technologies.

Online education, also known as elearning, has gained importance in recent years due to the advantages over learning in the classroom regarding important saves on time, labour intensiveness, and material resources involved in running e-learning environments. E-learning enables students to learn in a self-regulated manner and allows liberating interactions between learners and instructors, or learners and learners, from limitations of time and space through the asynchronous and synchronous learning network model [1].

Initial online learning was based on the use of what it is known as Web 1.0. With Web 1.0, Internet was used to provide

\footnotetext{
* The authors wish acknowledge the financial support received from the Educational Support Unit (USE), P1•1B2010-13 project through the Universitat Jaume I and Sustainability and Corporate Social Responsibility Master Degree (UJI - UNED).
} 
communication between teachers and students in a manner that students were mainly passive consumers of content delivered by teachers. The evolution of Web 1.0 to Web 2.0 has propitiated the application of e-learning in a more interactive manner. Furthermore, new Web programming technologies allow the easy development of Web 2.0 applications that can be used for e-learning specific purposes.

Within this context, the main purpose of this work is to present successful learning experiences based on creativity, innovation and the use of Information and Communications Technologies (ICT) to develop training practices in the area of Corporate Social Responsibility (CSR). In particular, the experiences consist of the development of an ontology of Corporate Governance and a case method based on the management of the relationships among stakeholders. The rest of this paper is structured as follows. Section 2 reviews the theoretical background related to topics involved in the learning experience presented in this paper. In section 3 , it is described the experiences, presenting the activities and summarising the results. Finally, section 4 presents the main conclusion of the study.

\section{Theoretical background}

Collaborative or group learning generally refers to instructional methods that encourage students to work together on academic tasks [2]. In collaborative learning, learners are typically supposed to construct knowledge by working on complex problems together, including individually contributing to solving the problem, partaking in discussion of the individual contributions, and arriving at joint solutions [3]. Attending to its definition, collaborative learning can be considered a part of what is known as social constructivism.

Constructivism is a theoretical foundation that supports a transforming from teacher-centred to a learner-centred in educational processes [4]. It provides a set of principles to create student-centred environments that support reflective processes in a manner that the educator plays the role of facilitator, while the learner's constructs reality through interactions with the environment. It proposes to give more significance to the learning contexts as an alternative to the memorization. This permits to build knowledge, doing activities closer to the real world and generally involves discussion groups [5].

Collaborative learning and constructivism principles can be successfully addressed with e-learning activities. Elearning can be defined as a web-based system that makes information or knowledge available to users or learners and disregards time restrictions or geographic proximity [1].

Initial uses of web in the context of elearning were limited to deliver documents or multimedia files to students, but current Web 2.0 platforms are nowadays seen to have an emerging role to transform teaching and learning [6]. Web 2.0 refers to the social use of the Web which allows people to collaborate, to get actively involved in creating content, to generate knowledge and to share information online [7]. This new use of web capabilities makes Web 2.0 to arise as a new trend of Internet which has many characteristics that support teaching and learning processes [8].

\section{Class experiences}

The learning experiences of this research were carried out with the support of two specific Web 2.0 applications designed by SoGReS Group [9], which allowed students to collaborate with the rest of students in an active, open and interactive manner. The e-learning activities were addressed to the students within the subject "CSR Management" of the "Master in Sustainability and Corporate Social 
Responsibility", which is offered by University Jaume I in Castellón (Spain) and UNED. The taught system of this master is completely online, and the use of ICT by students is therefore a transversal subject integrated in the programme.

\subsection{E-learning activity based on on- tologies}

In this activity, students were required to develop a domain ontology about one of the main topics of the subject, that is, Corporate Governance. The activity was structured in two main phases. In the first phase, students had to prepare a list of definitions of terms and to establish semantic relationships among them. In the second phase, they had to assess the definitions of their classmates by means of a process of voting, as well as making contributions to improve the definitions. Moreover, they had to review their initial definitions including the comments of their classmates. The aim of the training task was to reach a consensus about the key terms and definitions of Corporate Governance.

The results revealed that students increased their motivation in the subject, and showed their widely knowledge of Corporate Governance as well as learning of their classmates by means of a set of concepts and relationships among key terms of Corporate Governance. The majority of students proposed innovative definitions and they were correctly argued. Broadly speaking, the assessment obtained for first aspect ("definition of terms") was $92 \%$. Regarding to relation between terms, the results were positive and the average mark of second aspect ("relationship between terms") was $81 \%$. We observed that a significant number of students actively worked in the ontology of Corporate Governance, proposing and linking concepts according to their own knowledge, sharing their experience with their classmates and learning new terms of Corporate Govern- ance. All that work was supported with an intensive reflection and discussion process.

\subsection{E-learning activity based on a case method}

During the execution of the activity, students were required to contribute with their knowledge to the design of strategies the Public Administration could apply for the management of its stakeholders in a social responsible way. The activity was focused on the management of environmental issues by a small town council. The case development was structured in four main phases. During the first phase, students had to reflect on the environmental impacts derived from the town council activity, related to its town management and to its own management as organisation. Moreover, students had to indicate what stakeholders were associated to each impact and to explain the reasons for it. In the second phase, a voting process was carried out. The student had to give a limited amount of values $10,8,6,4,3,2,1$ - to the different environmental impacts, just considering the importance these impacts have in its opinion. In the following phase, taking the voting results, each student had to analyse the stakeholders associated to most relevant environmental impacts. In the final phase of the activity, students had to explain the actions and strategies he considered more appropriate for the management of the more relevant stakeholders by the public administration studied. These actions had to be consistent with the environmental impacts previously identified as important for these stakeholders.

The main results of this experience were related to the attitude of the student towards the subject and to the competencies these students had developed by means of the activity. First of all, the teachers observed an increase in the motivation of the student related to the issue. The students' contribution was higher than 
required for the assessment in each activity phase.

The use of ICT allowed students to collaborate and to get a view of the contributions of the classmates, even when they worked in different places and at different moments. For example, they could have a ranking of environmental impacts as a result of all their votes. The fact of adopting different roles (citizen, politician, etc.) gave the student different points of view of the problem analysed. Moreover, the students could better understand the management of the stakeholders' relations in a social responsible way by a public administration, noticing the range and complexity of this process.

\section{Conclusion}

This research finds evidence that Web 2.0 applications can be successfully used for educational purposes when they are carefully designed. According to the experiences presented in this paper and the obtained results, the authors suggest to use the Web 2.0 applications designed to provide support for ontologies and casemethod learning activities at virtual environments, since these applications may improve students' performance.

This learning methodology applied to different activities should be used in future courses in order to provide scientific validity to the benefits that it entails for students' learning process, not only regarding the knowledge they get, but also regarding the skills they develop, that include collaboration, critical thinking and ICT use among others. As Steve Hargadon [10] said: "Web 2.0 is the future of education".

\section{References}

[1] Sun, P.C., Tsai, R.J., Finger, G and Chen, Y.Y. "What drives a successful e-Learning? An empirical inves- tigation of the critical factors influencing learner satisfaction", Computers \& Education, 50, pp. 11831202, 2008

[2] Dillembourg, P. "Introduction: what do you mean by 'Collaborative Learning'?” In P. Dillembourg (Ed.), Collaborative learning: Cognitive and computational approaches, pp. 119, Amsterdam, Pergamon, 1999

[3] Roschelle, J., and Teasley, S. D. "The construction of shared knowledge in collaborative problem solving". In C. O’Malley (Ed.), Computer supported collaborative learning, Berlin: Springer, 1995.

[4] Young, L.E., Maxwell, B. "Teaching nursing: theories and concepts". In: Young, L.E., Paterson, B.L. (Eds.), Teaching Nursing: Developing a Student-Centered Learning Environment. Lippincott Williams and Wilkins, Philadelphia, 2007.

[5] Crook, Ch. "Ordenadores y aprendizaje colaborativo”. Madrid: Morata, 1998

[6] Alexander, B., Levine, A. “ Web 2.0 Storytelling. Emergence of a New Genre", In EduCAUSE Review. 43 (6), pp. 40-56, 2008

[7] Grosseck, G. "To use or not to use web 2.0 in higher education?", Procedia - Social and Behavioral Sciences, 1(1), pp. 478-482, 2009

[8] Ajjan and Hartshorne, R. "Investigating faculty decisions to adopt Web 2.0 technologies: Theory and empirical tests", The Internet and Higher Education, 11(2), pp.71-80, 2008

[9] León, R., Muñoz, M.J., and Chalmeta, R., "Building a Corporate Social Responsibility ontology using universal knowledge" In Proceedings $M I C$ 2010. Ankara, Turkey, 2010

[10] Hargadon, S. "Web 2.0 is the future of education". 2008. http://www. stevehargadon.com/2008/03/web-20is-future-ofeducation.html 
